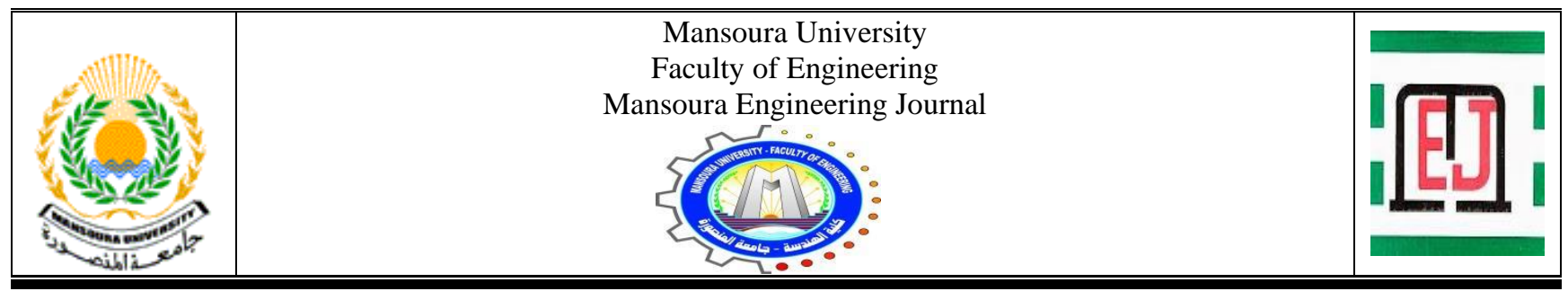

\title{
Dynamo Visual Programming-Based Generative Design Optimization Model for Construction Site Layout Planning
}

\author{
Mona Salah*, Emad Elbeltagi and Asser Elsheikh
}

\begin{tabular}{|l|}
\hline KEYWORDS: \\
Siterayout, \\
Construction Sites, \\
Temporary Facilities, \\
Site Logistics \\
Optimization, \\
Generative Designs \\
\\
\\
\end{tabular}

\begin{abstract}
Site layout is the front-end planning for construction sites, aiming for a safe and productive work environment. The layout planning is a complex optimization problem which involves identifying, sizing, and positioning temporary facilities within the construction site boundaries. The main concern in layout planning is the optimization process, in which designer searches among multiple solutions of locating site facilities and choose the best one. The layout optimization problem has been solved using Mathematical and Heuristic methods. This paper studies the applicability of using Visual Programming, Generative Design as the optimization technique, to search for the optimum site layout. As well as, the paper presents an initial development in site layout planning to serve as a foundation that could be enhanced through more future detailed research. In general, the study describes how to model the site and facilities by forming a simulation model applies the parametric visual programming concept through Dynamo-Revit software. Also, it describes the modeling of different geometric and safety constraints between temporary facilities. Then, discussing how the optimization process takes place through the generative design engine. To validate this new optimization technique and the performance of the developed model, a case study from literature is presented and the results are compared.
\end{abstract}

\section{INTRODUCTION}

$\mathrm{C}$ ONSTRUCTION site layout planning is the process of identifying the number and size of different temporary facilities (TFs) needed through the construction process and locating these facilities to satisfy the identified geometrical and safety constraints [43]. Site layout planning gained the interest of many researchers as a way for cost and time saving and improving safety in construction sites [29]. Poor site planning may increase the nonproductive time and unnecessary costs for relocating facilities and

Received: (15 September, 2021) - Revised: (28 December, 2021) Accepted: (29 December, 2021)

*Corresponding Author: Mona Salah, Teaching Assistant at the Civil Department, Faculty of Engineering at Horus University, Damietta, Egypt (Email: mabbas@horus.edu.eg) overhandling material.

Recently, construction industry experiences a change with the implementation of Building Information Modeling (BIM) at different planning phases of construction projects [27]. Also, a huge advancement in artificial intelligence field takes place, which enables computer to gain infinite computational capabilities, producing numerous design alternatives, where human designers have the experience to decide what the most suitable alternative is. This is what the BIM-Generative design (GD) stands for. This paper studies applying GD as an optimization technique to search for the most accurate and most safe site layout plan. The study motivation arises from different

Emad Elbeltagi, Professor of Construction Management, Mansoura University, Egypt (E- mail: eelbelta@mans.edu.eg)

Asser Elsheikh Structural Engineering Department, Mansoura University, Egypt. E-mail: assermfee@mans.edu.eg; Department of Civil Engineering, Peoples' Friendship University of Russia (RUDN University), Russia. E-mail: elsheykham@pfur.ru 
aspects, including:

- The need to optimize site layout plan to realize a minimum cost and work force layout in a more applicable and less time-consuming process;

- Introducing a non-traditional optimization technique suitable for solving such complex problems; and

- Applying visual programming concept to model, visualize and simulate the studied site plan.

This research presents an introduction to the GD and the main assumptions for adopting this engine in finding the optimum layout of TFs. The proposed technique is considered a new development of site layout to optimize the allocation of construction sites TFs. Then, applying the proposed model on a construction site layout case from literature to check its validity.

\section{LITERATURE REVIEW}

The process of site layout planning starts with selecting TFs needed for each construction phase, then sizing them. The desired inter-relationships among facilities are then identified and finally allocating these facilities within the site boundaries according to the identified geometrical and safety constraints. Many optimization models were developed during the past years, mainly aiming to reduce project costs through proper and well-organized layouts. According to [15] previous construction site layout planning researches target either:

- Constructing a model of different site facilities and obstacles,

- Finding optimum solutions for facilities' locations.

- Searching for a more suitable optimization technique.

- Optimizing the sizes of facilities with dynamic nature.

- Applying more accurate proximity measures.

- Examining various objective functions.

- Investigating the time effect on variables of site layout planning.

- Simulating the construction process to validate the layout plan.

Optimization of construction site layout is commonly solved by heuristic algorithms including: Genetic Algorithms (GAs), Ant Colony Optimization (ACO), Artificial Bee Colony Optimization, Particle Swarm Optimization (PSO), Harmony Search (HS), Cutting Plane Algorithm (CPA), Max-Min Ant System (MMAS), and Simulated Annealing (SA). Said and ElRayes [47], compared the performance of two site layout dynamic models by applying GAs and approximate dynamic programming and found that the later method outperformed GAs in terms of effectiveness in reaching more near optimum solutions and efficiency in reducing computational time. However, [47] concluded that GA is easy to apply and would be more preferable for large-sized and multi-objective optimization problems. Yi et al. [51] developed a mathematical optimization model to deal with a large variety of practices as constraints or objectives. El-Rayes and Said [26] developed a robust model for dynamic site layout using approximate dynamic programming in order to minimize total layout costs.
Hammad et al. [9] used mixed integer nonlinear programming in order to minimize transportation costs and noise levels at the construction site. Also, Hammad et al. [35] used mixed integer programming to solve site layout problem and covering the presence of travel barriers. The presented models leveraged the optimization process within a suitable time frame for moderate sized site layout problems.

PSO is another optimization algorithm which simulates the social behavior of bird flocking to a desired place [42]. Zang and Wang [20] developed a PSO-based layout model to solve a single-objective static site layout optimization problem to allocate facilities of unequal area at predetermined locations. Also, $\mathrm{Xu}$ and $\mathrm{Li}$ [23] presented an approach that employs a multi-objective PSO algorithm to solve multi-objective dynamic layout problems. Cheng and Lien [37] presented a hybrid swarm intelligence-based particle-bee algorithm for single-objective optimization of site layout at predetermined locations.

The ACO is also another heuristic approach that simulates ants' behavior searching for food [31]. ACO is used for solving facility layout problem in a hypothetical medium sized construction site [25]. Gharaie et al. [14] and Lam et al. [25] employed ACO in solving static site layout problems in construction projects. Ning et al. [52] used Max-Min Ant System (MMAS) to solve dynamic construction layout planning. Kaveh [4] developed two meta-heuristic algorithms Colliding Bodies Optimization (CBO) and Enhanced Colliding Bodies Optimization (ECBO). Table (1) presents summary of previous literatures and the applied optimization algorithm in each.

TABLE 1

\begin{tabular}{l||c||c}
\multicolumn{2}{c}{ PREVIOUS LITERATURES' OPTIMIZATION TECHNIQUES } \\
Researcher & Year & $\begin{array}{c}\text { Optimization } \\
\text { Technique }\end{array}$ \\
\hline Hegazi and Elbeltagi & 2000 & GA \\
Tawfik and Fernando & 2001 & GA \\
Osman et al. & 2003 & GA \\
Gharaie et al. & 2006 & ACO \\
Lam et al. & 2007 & ACO \\
Zhang and Wang & 2008 & PSO \\
Calis and Yuksel & 2010 & ACO \\
Ning and Lam & 2013 & ACO \\
Ning et al. & 2010 & MMAS \\
Xu and Li & 2012 & PSO \\
Kumar and Chang & 2015 & GA +A* \\
McKendall et al. & 2006 & SA \\
Huang and Wong & 2015 & BMILP \\
Kaveh et al. & 2016,2018 & CBO + ECBO \\
Pourhassan and Raissi & 2017 & GA \\
Ning et al. & 2018 & ACO \\
Farmakis and & 2018 & GA \\
Chassiakos & 2019 & GA+ACO \\
Ning et al. & 2020 & GA \\
Singh and Delhi & &
\end{tabular}

Using previous optimization algorithms for site planning is efficient but lacks visualization and the power of information. BIM-based models are rich in information and present a 3D visualization of the site model which facilitates the layout planning. Kumar and Cheng [49] presented a BIM-based layout 
framework for congested construction sites utilizing information from a BIM model to estimate the required dimensions of each facility then, an algorithm is used to calculate the actual travel distances generating optimal solutions in conjunction with GA. Loss of data is a frequent problem occurs during construction planning phases, therefore the need for BIM arises to supply secure and consistent data [27]. To achieve that, designers add all relevant data into a 3D parametric model for the project. Once it is stored in the model, the information could be retrieved at any time [27].

Four-dimensional (4D) planning was also proposed in previous studies aiming to replicate the realistic cases of site planning. These cases comprise of a site 3D model integrated with the project schedule. Then, site layout planning is based on the generated 4D visualization of different construction activities [56]. Table (2) summarizes previous researches that utilized BIM in site layout planning.

TABLE 2

PRevious BIM-BASED RESEARCHES

\begin{tabular}{|c|c|c|}
\hline Researcher & Year & Subject \\
\hline Astour and Franz & 2014 & Site Layout Planning \\
\hline Kozlovska et al. & 2014 & Modelling Construction Site Facilities \\
\hline Kumar and Cheng & 2015 & $\begin{array}{l}\text { Congested construction site layout } \\
\text { planning }\end{array}$ \\
\hline Aziz et al. & 2016 & Facilities Management \\
\hline Hu et al. & 2016 & Construction and facility management \\
\hline Schwabe et al. & 2016 & Site Layout Planning and Scheduling \\
\hline Trani et al. & 2016 & Construction Site Planning \\
\hline Krepp et al. & 2016 & $\begin{array}{l}\text { Evaluation of construction methods, site } \\
\text { layouts and schedules }\end{array}$ \\
\hline Amiri et al. & 2017 & Site Layout Planning \\
\hline $\begin{array}{l}\text { Olugboyega and } \\
\text { Wemimo }\end{array}$ & 2018 & Site Layout Planning \\
\hline Liang et al. & 2018 & Site Layout and Equipment Monitoring \\
\hline Le et al. & 2019 & Site Layout Planning \\
\hline Singh et al. & 2019 & Site Layout Planning \\
\hline Bortolini et al. & 2019 & Logistic planning \\
\hline Dasovic et al. & 2019 & Facilities and tower cranes allocation \\
\hline Cheng and Chang & 2019 & Material layout planning \\
\hline $\begin{array}{l}\text { Alsaggaf and } \\
\text { Jrade }\end{array}$ & 2019 & Site Layout Planning \\
\hline Singh and Delhi & 2020 & Site Layout Planning \\
\hline
\end{tabular}

The generative design is a concept based on natural selection searching through the decision space for optimum design solutions. GD concept has been applied in many architectural and manufacturing applications. However, as per the authors knowledge, it has not been applied in the field of site layout planning. Monizza et al. [17] investigated the potentials of GD and parametric design in mass production though a pilot study in Glued-Laminated-Timber industry. Lobo et al. [22] applied BIM-Based GD in drywall installation planning in prefabricated construction field. The main objective of the present study is to introduce a non-traditional optimization technique, which is easier and more suitable for solving different site layout problems. As such, this paper develops a new optimization concept uses a GD engine searching for more accurate and safer layout plan.

\section{OPTIMUM CONSTRUCTION SITE LAYOUT}

Modeling the construction site layout as an optimization problem requires identifying the objective function, constraints, and variables. Also, it requires measuring the distances and identifying the closeness relationships between facilities or assuming trip frequencies. These issues are discussed in the next subsections.

\section{A. Objective Function}

In general, most layout plans have a main common objective which is reducing costs depending mainly on reducing distances among site facilities. Some literature assumed static site layout through the whole construction period. But most site facilities are only needed for a defined period of time through the construction period, therefore the site layout problem is a dynamic one. In this study, the total construction duration will be divided into phases which need different facilities in each phase. Equation (1) is a general equation to calculate total cost of transportation trips and relocation costs of TFs along different phases and mainly derived from [42], as follow:

$$
\begin{aligned}
& \text { Total Cost }(\mathrm{TC})= \\
& \qquad \sum_{t}^{p} \sum_{i}^{n-1} \sum_{j=i+1}^{n} D_{i j} W_{i j} F_{i j} E_{i j} \Delta_{t}+\sum_{t+1}^{p} \sum_{i}^{n} D_{i i}^{\prime} W_{i}^{\prime}
\end{aligned}
$$

Where:

TC: The total cost.

$D_{i j}$ : Distance between facility $\mathrm{i}$ and $\mathrm{j}$ in phase $\mathrm{t}$.

$D_{\text {ii }}^{\prime}$ : Distance between centroid of facility $i$ at phase $t$ and

the centroid of the same facility at phase $t+1$

$W_{i j}$ : Closeness relationship between facilities $\mathrm{i}$ and $\mathrm{j}$.

$W_{i}^{\prime}$ : Relocation weight for facility $i$.

$\Delta_{t}$ : The duration of the project phase $\mathrm{t}$.

$F_{i j}$ : frequency of transportation between facility $\mathrm{i}$ and $\mathrm{j}$ per day for the project phase.

$E_{i j}$ : cost per unit length between facilities $\mathrm{i}$ and $\mathrm{j}$.

$\mathrm{n}$ : total number of facilities.

P: total number of time phases.

Trip cost and frequencies are user defined parameters, and the travel distances are calculated according to the location of each facility. The objective function will be optimized to minimize the TC of transportation.

\section{B. Travel Distances}

In small projects, the simplest approach to calculate the distance between any two facilities is the direct approach, which uses the $\mathrm{X}-\mathrm{Y}$ coordinates to determine the distance between these two points, Figure (1). Euclidean distance is the straight line between any two points, while the rectilinear distance is the direct sum of $\mathrm{x}$ and $\mathrm{y}$ differences between them. The distance can be calculated using Equations (2) and (3), [30]. 
Euclidean Distance $=\sqrt{\left(X_{a}-X_{b}\right)^{2}+\left(Y_{a}-Y_{b}\right)^{2}}$

Rectilinear Distance $=\left|X_{a}-X_{b}\right|+\left|Y_{a}-Y_{b}\right|$

Where, $(X a, Y a)$ and $(X b, Y b)$ are the coordinates of points $a$ and $b$.

The main disadvantage of direct approach is that it does not consider the detours around site objects due to obstacles and other facilities, to move from one point to another, [30]. However, it suits small sized projects. This study uses the rectilinear approach to calculate distances between different facilities.

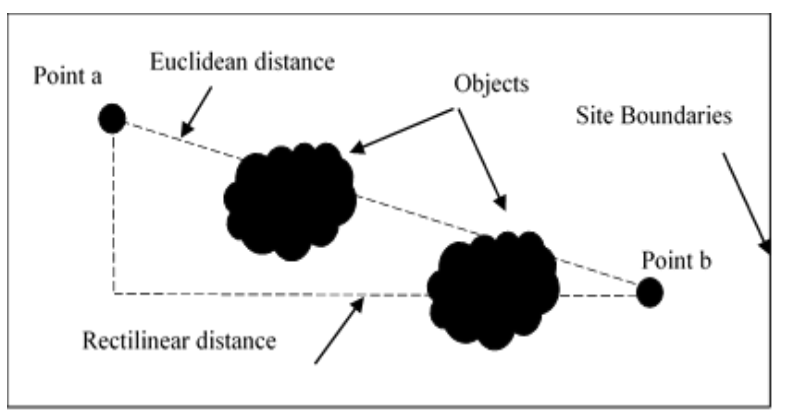

Fig. 1. Euclidean and Rectilinear Distances

\section{Facility Closeness and Spatial Relationships}

There is no standard limit to define how close or far a defined facility should be located from other facilities, when considering productivity, project cost, and safety. These closeness relationships represent the site planner's preference in locating site facilities near or far from one another. Closeness relationships can be represented according to the expected number of trips between the two facilities or by defining the closeness weights between them. Then, facilities with higher closeness weights or higher trip frequencies, will be located close to each other to save operational time. Some previous literature uses only closeness weights or trip frequencies, and some other assume both frequencies and weights based on their previous experience. Table (3) shows an example of closeness wights used in literatures [24, 21].

TABLE 3

TEMPORARY FACILITIES' ClOSENESS WeIGHTS

\begin{tabular}{l||l}
\multicolumn{1}{c||}{ The Closeness Relationship } & \multicolumn{1}{c}{ Closeness Weights } \\
\hline Absolutely Necessary & 81 \\
\hline Especially Important & 37 \\
\hline Important & 9 \\
\hline Ordinary Closeness & 3 \\
\hline Unimportant & 1 \\
\hline Undesirable & 0
\end{tabular}

\section{Geometric Constraints}

The main constraints applied in this study are: boundary, overlapping and distance constraints. Boundary constraint is to make sure that all site objects are within the site boundaries.

- To model the boundary condition: The corner points of each facility should be kept inside the site boundary; and there is no intersection between any side of facilities geometric shape and the boundary edges.

Overlap constraints should prevent any overlap between facilities within the same stage.

- To model overlap constraint: The intersection condition is applied and if it is true, the total cost function will be multiplied by a fixed high value as a penalty due to condition violation.

Distance constraints, user defined constraint, are concerned with the distances between facilities to satisfy a safe construction operation. In this research, a penalty is applied in case if any of the constraints is violated, the total cost is multiplied by an assumed fixed high value of $1,000,000$. While the optimization is processing, the layouts with higher costs will be eliminated.

\section{DYNAMO AND VISUAL PROGRAMMING MODEL}

Revit-Dynamo software is used in this research to execute the developed simulation-parametric model and then exports it to the GD engine. Dynamo enables parametric modeling; allowing designers to model and perform analysis on more complex shapes and geometries in Revit by formulating parametric data and relationships instead of drawing. Dynamo combines the mostly graphical approach in Revit with the powerful algorithmic techniques in scripting. The main advantage of using Dynamo is that users don't need to have a high level of programming syntax scripting or in generating complex shapes. Nodes are connected to represent the sequence of actions the program will execute.

Visual programming (VP) is a programming language in which users can create different programs by manipulating its elements graphically rather than by identifying them textually. Instead of writing a code script from scratch, the developer can assemble relationships by connecting ready customized nodes together to build an algorithm as shown in Figure (2). The figure shows a very simple arithmetic process script to add two numbers " $3,5.5$ ". The first part of this process is defining the used variables, which are defined as number nodes. The number node means that the variable entered is even a float value " 5.5 " or an integer value " 3 ". The second part represents the operation node that add the first variable to the second one. While the third part is the watch node which is used to visualize the output of a node.

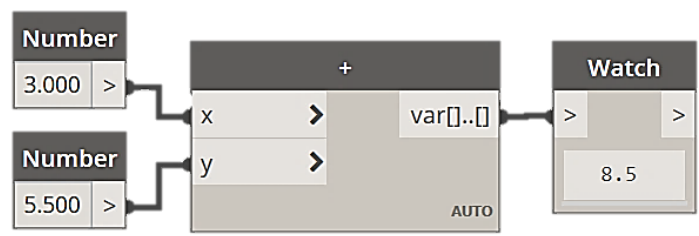

Fig. 2. Dynamo Algorithm to Add Two Numbers

\section{A. Modeling Construction Site Facilities}

With Dynamo, site facilities could be modeled as rectangular shapes or any other irregular shape as defined by the user and then could be patched into $3 \mathrm{~d}$ cubes. In General, rectangular surface is the most used geometrical shape in layout modeling. It can be used in modeling different site facilities 
such as workshops, caravans, parking lots, storage areas, restrooms, etc. The Rectangle node is used, which requires three main inputs: the plane required for the shape, the facility width and length. The plane to draw any geometric shape is the $\mathrm{X}, \mathrm{Y}$ plane. The width and length of the facility are user inputs through a number node which was described previously, or it could be linked from an excel sheet right to the model. The facility geometric shape is defined as a curve, then transformed into a surface by using a patching node as described in Figure (3).

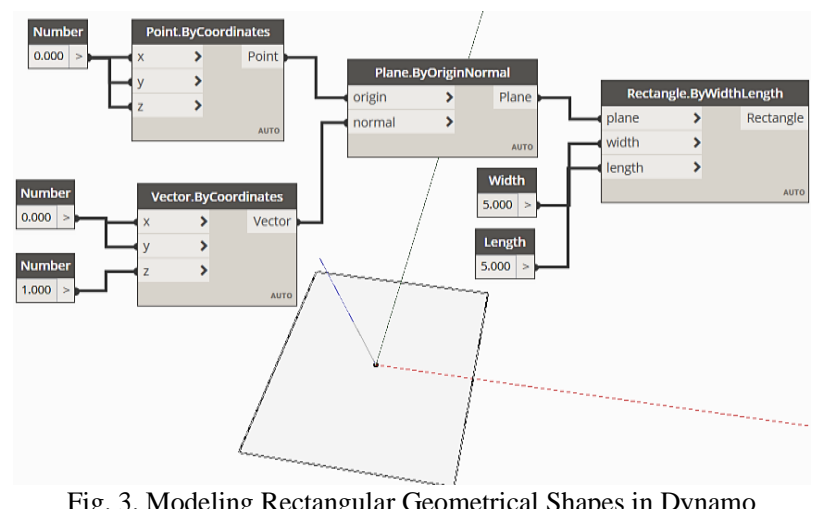

\section{B. Optimization by Generative Design}

Generative design is based on the natural selection to search through the decision space for optimum solutions. GD employs basics of GAs for a random yet directed search for the global optimum or near optimum solution from an infinite number of possible solutions. Usually, any solution is represented as a string named a chromosome. Once the objective function and the chromosome are set, an evolutionary procedure takes place through three genetic operators: Reproduction, Crossover and Mutation. In the reproduction process, fittest chromosomes receive better copies in new generations and lower fitness chromosomes are eliminated with a constant total number of chromosomes in each generation.

Through crossover, chromosomes are mixed in a random order by selecting two chromosomes (parent), then exchanging their information, to produce off-springs. The third operator is mutation, the process that resembles sudden generation of an odd off-spring turned-out to be genius [13]. The mutation process can break any stagnation in the process of evolution to locate the global optima. Refinery is an add-in to DynamoRevit which was lately improved to be a GD plug-in for Revit. Refinery is a GD beta for Autodesk mainly used at architecture, engineering and construction industry. It is the environment for applying the genetic optimization in this study. The user will be able to set the whole optimization process, defining the objectives (maximization or minimization of assumed objective functions), entering the inputs, defining the population size, and the main constraints.

GD performs several runs changing the input variables in every run. In each run the defined objective function is calculated and analyzed, and the runs are iterated till reaching the defined number of runs. While using Refinery, all variables connected to the input data must be Number Slider parameters. Number slider is a node where an assumed list of variables is created by defining the min, max and step values as shown in Figure (4). The values of $x$ and $y$ facilities coordinates in this model take a random value from this assumed number slider list with a main constraint within the site coordinates. The optimization process begins, optimizing one or more objective functions defined by different variables and constraints as the final functions value will be considered as the output of the process and defined as a number node or a watch node.

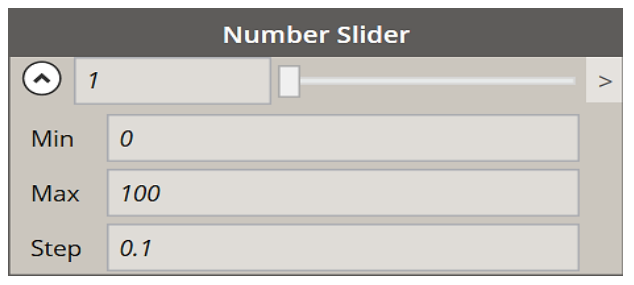

Fig. 4. Number Slider Node

\section{CASE STUDY}

To verify the proposed technique, a case study from the literature is solved and the obtained results are compared with previously reported results. The case study is a construction site with dimensions $20 \times 10$ meters with two consecutive phases each phase lasts for two days. The same case study was solved by $[42,26]$. The project requires a total of 7 TFs to assist the construction activities through its phases. The required TFs are user predefined according to the project requirements along with their dimensions as presented in Table (4). Two TFs (F2 and F5) have predetermined locations for the first phase-fixed in position- while the rest of facilities could be allocated anywhere through the site space and re-located to different positions in next project phases with an addition relocation cost as given in Table (4). For safety purposes, facility "F1" is a hazardous source that needs to be located at least 8 meters from facility "F3" in the $\mathrm{x}$ direction, [42]. The assumed closeness weights at each phase are listed in Tables (5 and 6), respectively. The main objective function is derived from Equation (1), as given in Equation (4). The distances are measured as rectilinear distances between facilities centroids.

(TC) $=\sum_{t}^{p} \sum_{i}^{n-1} \sum_{j=i+1}^{n} D_{i j} W_{i j} \Delta_{t}+\sum_{t+1}^{p} \sum_{i}^{n} D_{i i}^{\prime} W^{\prime}{ }_{i}$

Where:

TC: Total cost.

$D_{i j}$ : Distance between facility $\mathrm{i}$ and $\mathrm{j}$ in phase $\mathrm{t}$.

$\mathrm{D}_{\mathrm{ii}}^{\prime}$ : Distance between centroid of facility $\mathrm{i}$ at phase $\mathrm{t}$ and

the centroid of the same facility at phase $t+1$

$W_{i j}$ : Closeness relationship between facilities $\mathrm{i}$ and $\mathrm{j}$.

$W_{i}{ }_{i}$ : Relocation weight for facility i.

$\Delta_{t}$ : The duration of the project phase $\mathrm{t}$.

$\mathrm{n}$ : total number of facilities.

P: total number of time phases. 
TABLE 4

DEFINED TEMPORARY FACILITIES

\begin{tabular}{|c|c|c|c|c|c|c|}
\hline \multirow{2}{*}{ FACILITY } & \multicolumn{2}{|c|}{ Dimensions } & \multirow{2}{*}{ Location } & \multirow{2}{*}{ Coordinates } & \multirow{2}{*}{$\begin{array}{c}\text { Time } \\
\text { Phases }\end{array}$} & \multirow{2}{*}{$\begin{array}{l}\text { Relocation } \\
\text { Costs } \$ / \mathrm{m}\end{array}$} \\
\hline & $\mathbf{x}$ & $\mathbf{y}$ & & & & \\
\hline$F 1^{*}$ & 8 & 8 & - & - & 1,2 & 75 \\
\hline$F 2$ & 2 & 1 & Predetermined, 'Phase 1' & $(16,8.5)$ & 1 & 0 \\
\hline$F 3^{*}$ & 2.8 & 2.8 & - & - & 2 & 50 \\
\hline F4 & 4 & 2 & - & - & 1,2 & 75 \\
\hline F5 & 4 & 2 & Predetermined, 'Phase 1' & $(11,6)$ & 1 & 0 \\
\hline F6 & 4 & 3 & - & - & 2 & 75 \\
\hline F7 & 4 & 2 & - & - & 2 & 50 \\
\hline
\end{tabular}

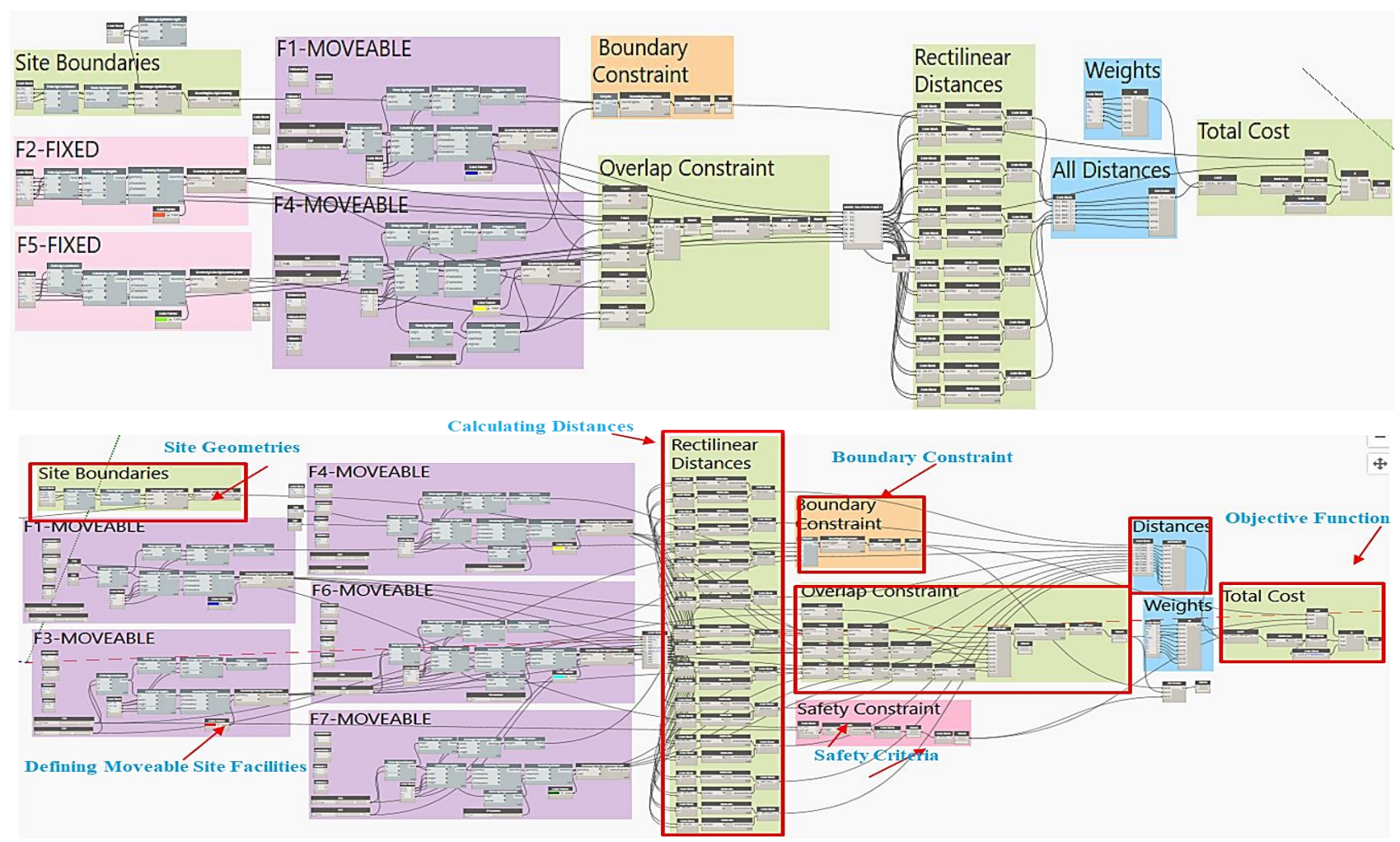

Fig. 5. The Dynamo Simulation Model for The Case Study Phases

TABLE 5

Closeness Weights Between Facilities "Stage 1"

\begin{tabular}{l||l||l||l||l||l||l||l} 
& F1 & F2 & F3 & F4 & F5 & F6 & F7 \\
\hline$F 1$ & 0 & 50 & 0 & 0 & 25 & 0 & 0 \\
\hline$F 2$ & & 0 & 0 & 100 & 0 & 0 & 0 \\
\hline$F 3$ & & & 0 & 0 & 0 & 0 & 0 \\
\hline$F 4$ & & & & 0 & 75 & 0 & 0 \\
\hline$F 5$ & & & & & 0 & 0 & 0 \\
\hline$F 6$ & & & & & & 0 & 0 \\
\hline$F 7$ & & & & & & & 0
\end{tabular}

TABLE 6

Closeness Weights Between Facilities "Stage 2"

\begin{tabular}{l||l||l||l||l||l||l||l} 
& F1 & F2 & F3 & F4 & F5 & F6 & F7 \\
\hline$F 1$ & 0 & 0 & 100 & 75 & 0 & 0 & 0 \\
\hline$F 2$ & & 0 & 0 & 0 & 0 & 0 & 0 \\
\hline$F 3$ & & & 0 & 100 & 0 & 0 & 0 \\
\hline$F 4$ & & & & 0 & 0 & 0 & 0 \\
\hline$F 5$ & & & & & 0 & 0 & 0 \\
\hline$F 6$ & & & & & & 0 & 0 \\
\hline$F 7$ & & & & & & & 0
\end{tabular}


For each phase, a simulation parametric model is constructed in Dynamo, as shown in Figure (5). The Dynamo model visualizes and simulates a proposed general layout plan for the site and connect between different main parameters of the problem. The visual programming applies a left to right flow to execute any algorithm. In this parametric model, the site geometry and facilities are modeled, where fixed facilities are assigned to predefined locations and other facilities are allocated at preliminary assumed visible locations inside site boundaries. The rectilinear distances between TFs centroids are calculated by a visual Dynamo algorithm, then the model calculates the total cost of the layout plan according to Eq. (4). The constraints are modeled by a visual algorithm and connected to the main objective function. In this study, a penalty is applied if any of the constraints is violated, where the total cost is multiplied by an assumed fixed high value of $1,000,000$. The constraints are identified as:

- boundary constraint, to ensure that all facilities are allocated inside site boundaries,

- overlap constraint, to restrict site facilities to overlap each other's, and

- safety constraint, to permit a minimum distance between two facilities for hazard prevention.

After the model formulation, it is exported to the GD engine, thus the optimization process can take place. The $\mathrm{x}$ and $\mathrm{y}$ coordinates along with the facilities orientation angle $\left(0^{\circ}\right.$ or $90^{\circ}$ ) are the main input variables. All inputs are number slider nodes, hence the optimization engine could search among this number ranges for the optimum values of $\mathrm{x}$ and $\mathrm{y}$ coordinates along with the most suitable angle to place the TFs horizontally (orientation angle $=0^{\circ}$ ) or vertically (orientation angle $=90^{\circ}$ ). The total cost (objective function) is the prime output and defined as a watch node. The solution range of this problem is infinity as the TFs locations have the possibility of an infinite number of points through the site.

As illustrated in Figure (6), to start an optimization process a case study is selected from the exported dynamo models. GD needs a clear definition of all inputs and prime outputs as defined at the dynamo interface. For each phase of the case study, an optimization process is conducted to minimize the total costs. Setting the main optimization parameters (population size, number of generations and the assumed randomization seed) is a must in order to start the optimization process. Generative Design executes several runs (generations), in each run the input variables are changed and the main objective function is calculated. Each generation has a number of generated solutions (population). The optimization engine select the best solutions from each run. The iterations proceed till reaching the total number of defined generations as a stopping criteria. Higher values of population and generation number would give more optimum solutions for the problem yet consume more time and effort. The prime aim of the seed

number is to generate a randomized spread for the iterated generation. The layouts in Figures (7 and 8) are the optimum layouts at the two project phases according to [42], [26] respectively. Figure (9) shows the optimum layouts from the developed GD model. Figure (9a) shows the optimum layout for phase (1), where the generated solution gives a total cost of $\$ 2,742.5$. While Figure (9b) shows the optimum layout plan for phase (2) that gives total cost of $\$ 4,822$ taking into consideration the relocation cost of facility $\mathrm{F} 4$ and also this optimum layout maintains the safety distance constraints.

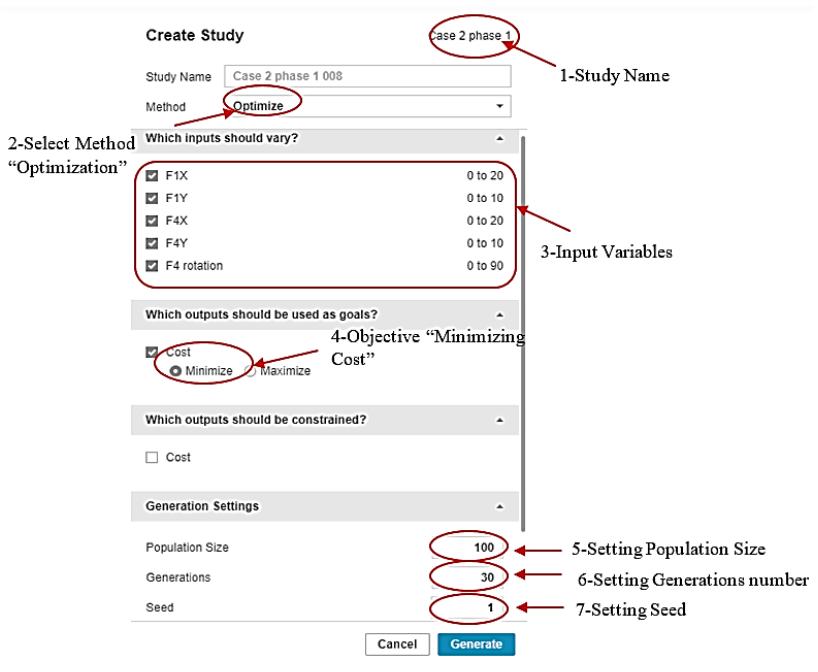

Fig. 6. Setting Optimization Parameters

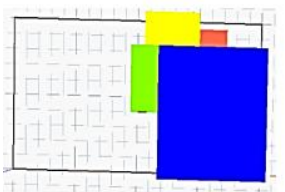

a) Layout for Phase "1"

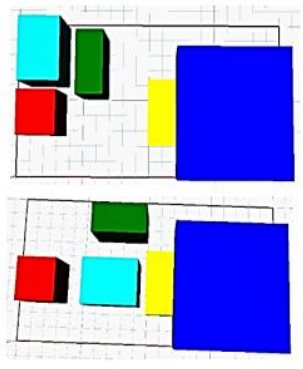

b) Layout for Phase "2"

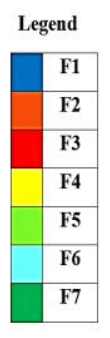

Fig. 7. The Results from Zouein and Tommelein [42]

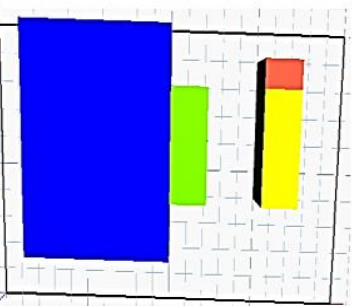

1) Layout for Phase "1"

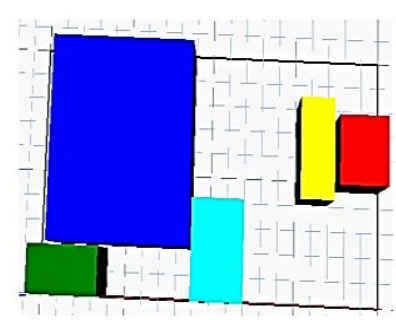

2) Layout for Phase "2"
Fig. 8. The Results from El-Rayes (2009) [26] 


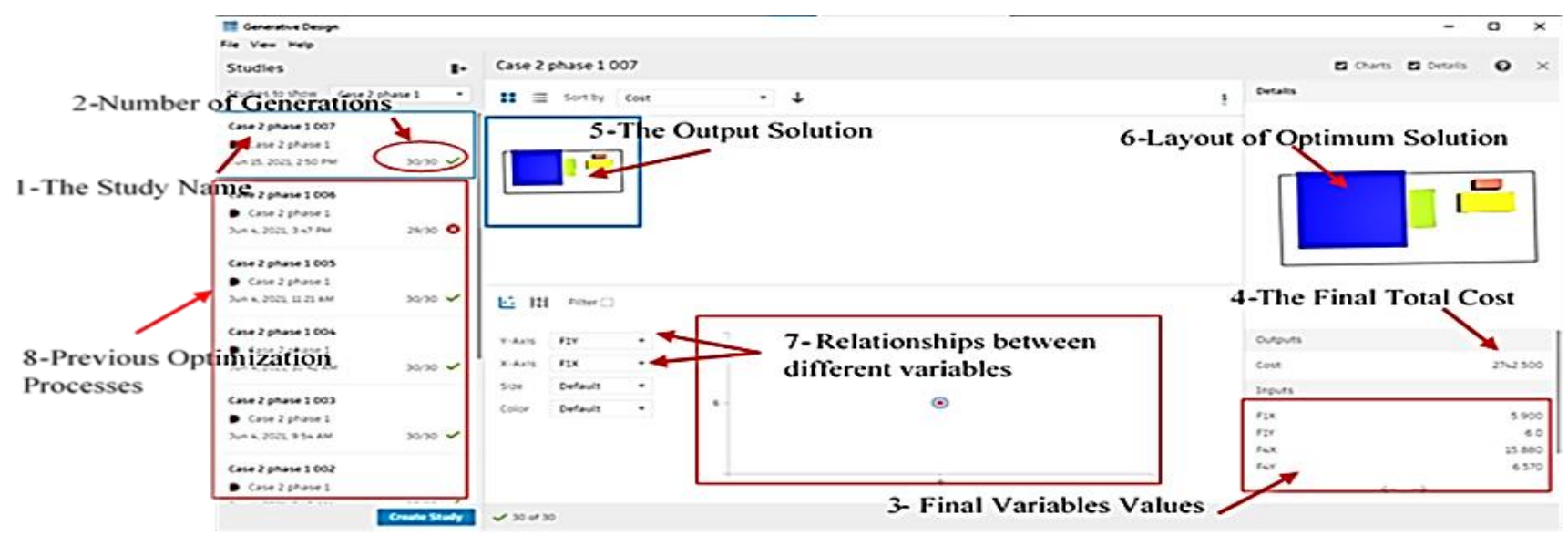

a) Phase "1"

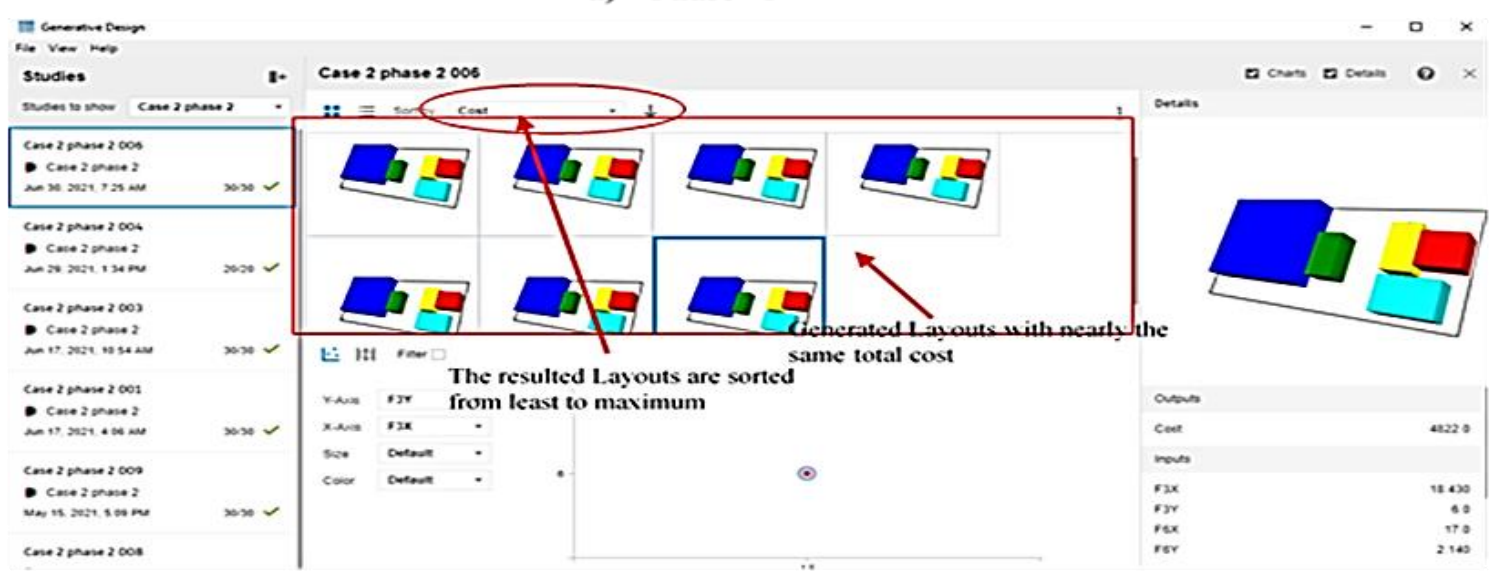

b) Phase "2"

Fig. 9. Results of the Optimization from the GD Engine

TABLE 7

COMPARING RESUltS WITH PREVIOUS RESEARCHES

\begin{tabular}{|c|c|c|c|}
\hline Algorithm & Phase & Cost \$ & Total Costs \$ \\
\hline \multirow{2}{*}{$\begin{array}{l}\text { Current } \\
\text { Model }(G D)\end{array}$} & Phase 1 & $2,742.5$ & \multirow{2}{*}{$7,564.5$} \\
\hline & Phase 2 & 4,822 & \\
\hline \multirow{3}{*}{$\begin{array}{l}\text { Zouein and } \\
\text { Tommelein } \\
1999\end{array}$} & Phase 1 & 2.250 & \multirow{3}{*}{7,885} \\
\hline & Phase 2 layout "1" & 5.635 & \\
\hline & Phase 2 layout "2" & 5.635 & \\
\hline \multirow{2}{*}{ Said (2010) } & Phase 1 & 2,900 & \multirow{2}{*}{7,750} \\
\hline & Phase 2 & 4,850 & \\
\hline
\end{tabular}

Table (7) compares the results of the two previous optimization techniques and the proposed GD model. Considering previous results, Zouein and Tommelein [42], developed a linear programming model which gave the least cost layout at the first phase when the variables were only the coordinates of facilities F1 and F4. However, at the second phase the linear programming model generated a layout with higher cost as the variables increased to cover a bigger range of facilities F1, F3, F4, F6, and F7. Which means that the linear model does not efficiently work with large number of variables.
El-Rayes and Said [26], applied the basics of approximate dynamic programming to optimize the presented case study and the model gave near optimum layouts for both phases in this dynamic case. The results of El-Rayes and Said [26], were less in total costs than what is generated from [42]. The utilized GD model managed to develop the least cost dynamic layout when compared with the layouts presented in the former studies, what approves the applicability and capabilities of the developed GD model as an efficient tool for site layout optimization problems.

\section{LIMITATIONS AND RECOMMENDATIONS}

This paper presented a site layout planning model based on GD as an optimization tool. The study applied a single objective optimization problem to validate the effectiveness of the GD engine as an optimization tool. For future research, the developed site layout planning model would be enhanced to handle the site layout as a multi-objective optimization problem taking into consideration safety criteria, noise levels and environmental impacts. Also, the distances could be modified to represent the actual routes between site facilities. In addition, the current model could be programmed as an add-in to a BIM software environment by applying the basics of Application Programming Interface (API). This API development would 
form a revolution in the site planning sector. A ready BIM addin for different software such as Revit that allows an organized and predefined environment to model and optimize site facilities layout.

\section{CONCLUSIONS}

The following conclusions are drawn from this study:

A) The presented paper developed a BIM simulation model within the Dynamo visual programming environment to utilize its powerful functions and apply it for optimal location of construction site facilities.

B) The study illustrated how to represent boundary, overlapping and other safety constraints within the Dynamo environment to calculate the required total cost objective function.

C) The study discussed and proved the applicability of applying the new BIM-GD model as a new approach in optimizing construction site layout planning problems.

D) The study concluded that the new developed BIM-GD model is a very practical tool to simplify the optimization process.

E) BIM provided a very powerful environment for modeling, simulating and optimizing construction site layouts in a simpler and less effort process.

F) A case study from literature was applied to validate and prove the applicability of the proposed technique which gave better results than literature.

G) The main powerful points, limitations. and some future adjustments are outlined to give a fully corrected optimization environment.

\section{AUTHORS CONTRIBUTION}

M. Salah, E. Elbeltagi and A. Elsheikh conceived the outline picture of the presented idea.

M. Salah developed and designed the study model and theory, collected all needed data and resources then performed the computations.

M. Salah drafted the article and E. Elbeltagi verified the analytical methods, supervised and critically revised the paper. E. Elbeltagi encouraged M. Salah to investigate the main points and supervised the results of this work.

All of the authors contributed to get the final manuscript.

\section{FUNDING STATEMENT:}

The author did not receive any financial support of the research authorship and publication of this article.

\section{DECLARATION OF CONFLICTING INTERESTS STATEMENT:}

The author declared that there are no potential conflicts of interest with respect to the research authorship or publication of this article.

\section{REFERENCES AND FOOTNOTES}

[1] A. Alsaggaf, and A. Jrade. "ARCSPAT: AN INTEGRATED BIM-GIS MODEL FOR SITE LAYOUT PLANNING." Proceedings, Annual Conference-Canadian Society for Civil Engineering. 2019.

[2] A. Colorni, et al. "Heuristics from nature for hard combinatorial optimization problems." International Transactions in Operational Research 3.1 (1996): 1-21.

[3] A. Kaveh, et al. "Construction site layout planning problem using two new meta-heuristic algorithms." Iranian journal of science and technology, transactions of civil engineering 40.4 (2016): 263-275.

[4] A. Kaveh. "Applications of metaheuristic optimization algorithms in civil engineering. " Basel, Switzerland: Springer International Publishing, 2017.

[5] A. Kaveh, M. R. Moghaddam, and M. Khanzadi. "Efficient multiobjective optimization algorithms for construction site layout problem." Scientia Iranica 25.4 (2018): 2051-2062.

[6] A. M. Adrian, A. Utamima, and K. J. Wang. "A comparative study of GA, PSO and ACO for solving construction site layout optimization." KSCE Journal of Civil Engineering 19.3 (2015): 520-527.

[7] A. R. McKendall Jr, J. Shang, and S. Kuppusamy. "Simulated annealing heuristics for the dynamic facility layout problem." Computers \& operations research 33.8 (2006): 2431-2444.

[8] A. R. Singh, and V. S. K. Delhi. "Automated BIM Based SLP for Construction Sites." Construction Research Congress 2020: Computer Applications. Reston, VA: American Society of Civil Engineers, 2020

[9] A. W. A. Hammad, A. Akbarnezhad, and D. Rey. "A multi-objective mixed integer nonlinear programming model for construction site layout planning to minimize noise pollution and transport costs." Automation in Construction 61 (2016): 73-85.

[10] B. Dasović, M. Galić, and U. Klanšek. "Active BIM approach to optimize work facilities and tower crane locations on construction sites with repetitive operations." Buildings 9.1 (2019): 21.

[11] C. Huang, and C. K. Wong. "Optimization of site layout planning for multiple construction stages with safety considerations and requirements." Automation in Construction 53 (2015): 58-68.

[12] C. J. Liang, V. R. Kamat, and C. M. Menassa. "Real-time construction site layout and equipment monitoring." Construction Research Congress 2018. 2018.

[13] D. E. Goldberg, B. Korb, and K. Deb. "Messy genetic algorithms: Motivation, analysis, and first results." Complex systems 3.5 (1989): 493530 .

[14] E. Gharaie, A. Afshar, and M. R. Jalali. "Site layout optimization with ACO algorithm." Proceedings of the 5th WSEAS International Conference on Artificial Intelligence, Knowledge Engineering and Data Bases. 2006.

[15] Farmakis and M. Panagiotis "Genetic algorithm optimization for dynamic construction site layout planning." Organization, technology \& management in construction: an international journal 10.1 (2018): 16551664.

[16] G. Calis, and O. Yuksel. "A comparative study for layout planning of temporary construction facilities: optimization by using ant colony algorithms." Proceedings of the 13th International Conference on Computing in Civil and Building Engineering, Nottingham, UK. 2010.

[17] G. P. Monizza, C. Bendetti, and D. T. Matt. "Parametric and Generative Design techniques in mass-production environments as effective enablers of Industry 4.0 approaches in the Building Industry." Automation in Construction 92 (2018): 270-285.

[18] H. Astour, and V. Franz. "BIM-and simulation-based site layout planning." Computing in Civil and Building Engineering (2014). 2014. 291-298.

[19] H. M. Tawfik, and T. Fernando. "A parallel genetic algorithm for optimizing construction site layouts." IASTED Int. Conf. Applied Simulation and Modelling, Marbella, Spain. 2001.

[20] H. Zhang, and J. Y. Wang. "Particle swarm optimization for construction site unequal-area layout." Journal of construction engineering and management 134.9 (2008): 739-748.

[21] I. H. Osman, B. Al-Ayoubi, and M. Barake. "A greedy random adaptive search procedure for the weighted maximal planar graph problem." Computers \& industrial engineering 45.4 (2003): 635-651.

[22] J. D. Cuellar Lobo, et al. "Building Information Modelling-(BIM-) Based Generative Design for Drywall Installation Planning in Prefabricated Construction." Advances in Civil Engineering 2021. 
[23] J. Xu, and Z. Li. "Multi-objective dynamic construction site layout planning in fuzzy random environment." Automation in construction 27 (2012): 155-169.

[24] K. Alagarsamy, Karthick. "CONSITEPLAN-A Multi-Objective Construction Site Utilization Planning Tool. " Diss. 2012.

[25] K. C. Lam, X. Ning, and T. Ng. "The application of the ant colony optimization algorithm to the construction site layout planning problem." Construction Management and Economics 25.4 (2007): 359-374.

[26] K. El-Rayes, and H. Said. "Global optimization of dynamic site layout planning in construction projects." Construction Research Congress 2009: Building a Sustainable Future. 2009.

[27] K. Schwabe, S. Liedtke, M. König, and J. Teizer. "BIM-based construction site layout planning and scheduling." International Conference on Computing in Civil and Building Engineering (ICCCBE). 2016.

[28] L. C. Lien, and M. Y. Cheng. "A hybrid swarm intelligence-based particle-bee algorithm for construction site layout optimization." Expert systems with applications 39.10 (2012): 9642-9650.

[29] M. Andayesh, and F. Sadeghpour. "Dynamic site layout planning through minimization of total potential energy." Automation in construction 31 (2013): 92-102

[30] M. Andayesh, and F. Sadeghpour. "The time dimension in site layout planning." Automation in construction 44 (2014): 129-139.

[31] M. Dorigo, V. Maniezzo, and A. Colorni. "Ant system: optimization by a colony of cooperating agents." IEEE Transactions on Systems, Man, and Cybernetics, Part B (Cybernetics) 26.1 (1996): 29-41.

[32] M. Kozlovska, J. Cabala, and Z. Struková. "The Methodology of Interactive Parametric Modelling of Construction Site Facilities in BIM Environment." Selected Scientific Papers: Journal of Civil Engineering $9.2(2014)$

[33] M.M. Singh, A. Sawhney, and A. Borrmann. "Integrating rules of modular coordination to improve model authoring in BIM." International Journal of Construction Management 19.1 (2019): 15-31.

[34] M. L. A. Trani, M. Cassano, and D. Todaro. "BIM design flow for construction site." EURO-MED-SEC-1. ISEC Press, 2016.

[35] M. Nadoushani, Z. Sadat, A. W. Hammad, and A. Akbarnezhad. "Location optimization of tower crane and allocation of material supply points in a construction site considering operating and rental costs." Journal of Construction Engineering and Management 143.1 (2017): 04016089.

[36] M. R. Pourhassan, and S. Raissi. "An integrated simulation-based optimization technique for multi-objective dynamic facility layout problem." Journal of Industrial Information Integration 8 (2017): 49-58.

[37] M. Y. Cheng, and L. C. Lien. "A hybrid AI-based particle bee algorithm for facility layout optimization." Engineering with Computers 28.1 (2012): 57-69.

[38] M.Y. Cheng, and N.W. Chang. "Dynamic construction material layout planning optimization model by integrating 4D BIM." Engineering with Computers 35.2 (2019): 703-720.

[39] N. D. Aziz, A. H. Nawawi, and N. R. M. Ariff, "Building information modelling (BIM) in facilities management: opportunities to be considered by facility managers." Procedia-Social and Behavioral Sciences 234 (2016): 353-362.

[40] O. Olugboyega, and O. T. Wemimo. "Construction site layout optimization and 3D visualization through BIM tools= Visualización 3D y optimización a través de herramientas BIM aplicado a los planos de proyecto." Building \& Management 2.2 (2018): 35-52.

[41] P. L. Le, T. M. Dao, and A. Chaabane. "BIM-based framework for temporary facility layout planning in construction site: a hybrid approach." Construction innovation (2019).

[42] P. P. Zouein, and I. D. Tommelein. "Dynamic layout planning using a hybrid incremental solution method." Journal of construction engineering and management 125.6 (1999): 400-408.

[43] P. P. Zouein, H. Harmanani, and A. Hajar. "Genetic algorithm for solving site layout problem with unequal-size and constrained facilities." Journal of computing in civil engineering 16.2 (2002): 143-151.

[44] R. Amiri, J. M. Sardroud, and B. G. De Soto. "BIM-based applications of metaheuristic algorithms to support the decision-making process: Uses in the planning of construction site layout." Procedia Engineering 196 (2017): 558-564.
[45] R. Bortolini, C. T. Formoso, and D. D. Viana. "Site logistics planning and control for engineer-to-order prefabricated building systems using BIM 4D modeling." Automation in Construction 98 (2019): 248-264.

[46] R. Eberhart, and J. Kennedy. "Particle swarm optimization." Proceedings of the IEEE international conference on neural networks. Vol. 4. 1995.

[47] S. Hisham, and K. El-Rayes. "Performance of global optimization models for dynamic site layout planning of construction projects." Automation in Construction 36 (2013): 71-78.

[48] S. Krepp, et al. "BIM site-towards a BIM-based generation and evaluation of realization variants comprising construction methods, site layouts and schedules." Proc. of the EG-ICE Workshop on Intelligent Computing in Engineering. 2016.

[49] S. Kumar, and J. C. P. Cheng. "A BIM-based automated site layout planning framework for congested construction sites." Automation in Construction 59 (2015): 24-37.

[50] T. M. Hegazy, and E. Elbeltagi. "Simplified spreadsheet solutions: A model for site layout planning." Cost Engineering, 42.1 (2000): 24-30.

[51] W. Yi, H. L. Chi, and S. Wang. "Mathematical programming models for construction site layout problems." Automation in construction 85 (2018): 241-248.

[52] X. Ning, K. C. Lam, and M. C. K. Lam. "Dynamic construction site layout planning using max-min ant system." Automation in construction 19.1 (2010): 55-65

[53] X. Ning, and K. C. Lam. "Cost-safety trade-off in unequal-area construction site layout planning." Automation in Construction 32 (2013): 96-103.

[54] X. Ning, et al. "A tri-objective ant colony optimization-based model for planning safe construction site layout." Automation in Construction 89 (2018): 1-12.

[55] X. Ning, et al. "Reducing noise pollution by planning construction site layout via a multi-objective optimization model." Journal of cleaner production 222 (2019): 218-230.

[56] Z. Ma, S. Qiping and J. Zhang. "Application of 4D for dynamic site layout and management of construction projects." Automation in construction 14.3 (2005): 369-381.

[57] Z. Z. Hu, J. P. Zhang, F. Q. Yu, P. L. Tian, and X. S. Xiang. "Construction and facility management of large MEP projects using a multi-Scale building information model." Advances in Engineering Software 100 (2016): 215-230.

\section{TITLE ARABIC:}

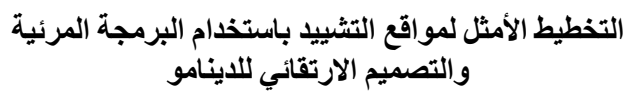

\section{ARABIC ABSTRACT:}

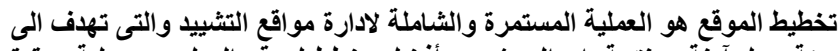

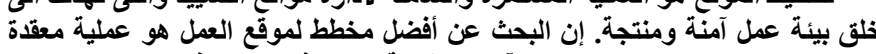

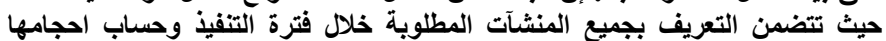

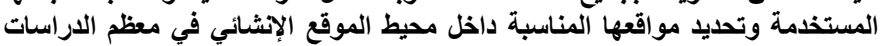

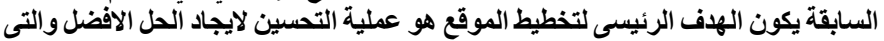

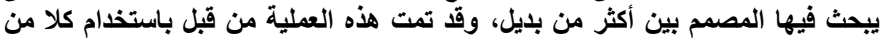

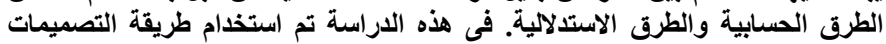

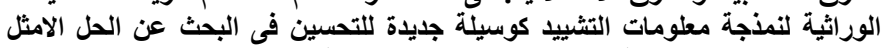

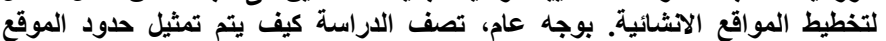

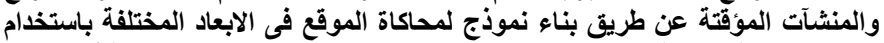

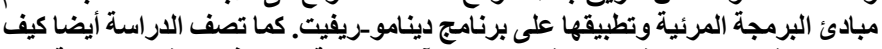

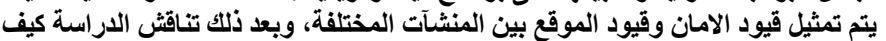

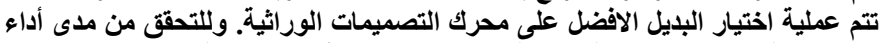

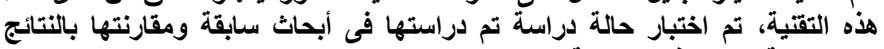
المستخرجة من نموذج الاراسة. 